\title{
Mitoxantrone, cisplatin, and methyl-glyoxal bis-guanylhydrazone chemotherapy for refractory malignant lymphoma: A Southwest Oncology Group Phase II trial
}

\author{
Bruce Dana ${ }^{1}$, Steve Dahlberg, ${ }^{2}$ Bertram Schnitzer, ${ }^{3}$ Carl R. Kjeldsberg, ${ }^{4}$ Stephen E. Jones, ${ }^{5}$ \\ Juan Carden, ${ }^{6}$ Richard Mundis, ${ }^{7}$ and Bill Tranum \\ ${ }^{1}$ Oregon Health Sciences University; ${ }^{2}$ Southwest Oncology Group Statistical Center - Seattle; ${ }^{3}$ University \\ of Michigan Medical Center; ${ }^{4}$ University of Utah Medical Center; ${ }^{5}$ Arizona Cancer Center; ${ }^{6}$ St. Louis \\ CCOP; ${ }^{7}$ Midwest CCOP; ${ }^{8}$ Arkansas CCOP
}

Key words: non-Hodgkin's lymphoma, chemotherapy, cisplatinum, mitoxantrone, methyl glyoxal bisguanyl hydrazone

\section{Summary}

A phase II trial of combination chemotherapy with mitoxantrone, cisplatin, and methyl-glyoxal bix-guanylhydrazone (MGBG) was conducted in 32 patients with unfavorable histology malignant lymphoma. All patients had relapsed after only one prior chemotherapy regimen (CHOP $-56 \%$; mBACOD $-28 \%$ ). There were three complete and eight partial responses (overall response rate $-34 \%$ ) among 32 eligible patients. The median duration of remission was 6.0 months. Severe granulocytopenia was common, with $19 / 32$ patients $(63 \%)$ suffering life-threatening, and $1 / 32(3 \%)$ suffering fatal, granulocytopenia.

We conclude that mitoxantrone-cisplatin-MGBG has modest activity as salvage treatment in malignant lymphoma patients, but produces severe toxicity.

\section{Introduction}

Although increasingly intensive chemotherapy programs for patients with unfavorable histology malignant lymphomas are producing increasingly higher complete remission and long-term disease free survival rates $[1-3]$, a significant number of patients fail induction therapy or relapse after complete remission.

Retreating these patients with front-line regimens rarely produces complete remissions or alters the clinical course $[4,5]$, so attention has focused on the use of standard drugs in newly designed combinations and on investigational drugs as salvage therapy. Single agents such as etoposide, cisplatin, mitoxantrone, m-AMSA, cytosine arabinoside, MGBG, VM-26, and the nitrosoureas have activity in lymphoma salvage. In various combinations, these drugs produce response rates of $30-40 \%$ [6-10]. Unfortunately, the responses are usually partial and brief.

The Southwest Oncology Group conducted a pilot study of cisplatin, MGBG and m-AMSA in patients with refractory unfavorable histology lymphomas [11]. A partial response rate of $43 \%$ was seen in 30 patients but the median response duration was only two months. Severe leukopenia, including one fatality, was the principal side effect.

In the present study, we substituted mitoxantrone for m-AMSA because of pre-clinical and phase II data suggesting good antilymphoma activity for this new anthracene analogue $[12,13]$, and synergism between mitoxantrone and cisplatin in animal tumor models [14]. Since the dose limiting 
Table 1. Characteristics and responses of 32 lymphoma patients receiving cisplatin, $\mathrm{MGBG}$, and mitoxantrone

\begin{tabular}{lc}
\hline & $\mathrm{N}$ \\
\hline Median age (range) & 62 yr $(18-92)$ \\
Sex & $19(59 \%)$ \\
Male & $13(41 \%)$ \\
Female & \\
Performance status & $16(50 \%)$ \\
0 & $16(50 \%)$ \\
1 & \\
Risk assessment & $10(31 \%)$ \\
Good & $22(69 \%)$ \\
Poor & \\
Prior therapy & $18(56 \%)$ \\
CHOP & $9(28 \%)$ \\
mBACOD & $5(15 \%)$ \\
other & \\
Histology & \\
DHL & $19(59 \%)$ \\
DUL & $3(9 \%)$ \\
DML & $3(9 \%)$ \\
DLPD & $7(22 \%)$ \\
Responses & \\
CR & $3(9 \%)$ \\
PR & $8(25 \%)$ \\
NR & $21(65 \%)$ \\
\hline
\end{tabular}

a DUL = diffuse undifferentiated lymphoma; DHL = diffuse histiocytic lymphoma; DML = diffuse mixed lymphocytichistiocytic lymphoma; DLPD = diffuse poorly differentiated lymphocytic lymphoma.

toxicity of mitoxantrone is the same as that of $\mathrm{m}$ AMSA, namely granulocytopenia, and since cisplatin and MGBG have a spectrum of non-overlapping toxicities we anticipated that the combination of cisplatin, MGBG, and mitoxantrone would be as safely tolerated as the combination given in our earlier study [11].

\section{Patients and methods}

Eligibility requirements to enter this study included a diagnosis of unfavorable histology malignant lymphoma refractory to no more than one prior chemotherapy regimen; measurable disease; performance status of 0,1 , or 2 (ECOG criteria); absolute granulocyte count $>2000 / \mu \mathrm{l}$; platelet count $>100,000 / \mu 1$; BUN $<20 \mathrm{mg} / \mathrm{dl}$ and serum creati- nine $<1.7 \mathrm{mg} / \mathrm{dl}$; fasting blood sugar $>60 \mathrm{mg} / \mathrm{dl}$; and a prior doxorubicin dose $<450 \mathrm{mg} / \mathrm{m}^{2}$. Patients were considered poor risk if they were $>65$ years of age, had known marrow involvement, had extensive prior irradiation to hematopoietic bone marrow, or had unexpectedly severe myelosuppression with prior chemotherapy.

The treatment program included mitoxantrone $12 \mathrm{mg} / \mathrm{m}^{2} \mathrm{IV}$, MGBG $500 \mathrm{mg} / \mathrm{m}^{2} \mathrm{IV}$, and cisplatin $50 \mathrm{mg} / \mathrm{m}^{2} \mathrm{IV}$, all given on day 1 and repeated at 21-day intervals. Poor risk patients received the same doses of MGBG and cisplatin but mitoxantrone was reduced to $10 \mathrm{mg} / \mathrm{m}^{2} \mathrm{IV}$. Doses of mitoxantrone and MGBG were escalated or reduced to achieve a granulocyte nadir count of $1000-1999 / \mu 1$ or a platelet nadir count of $75,000-99,999 / \mu 1$. An adequate trial of treatment required that two courses be given. Treatments were continued until tumor progression.

Standard response criteria were used [15].

\section{Results}

Thirty-five patients were registered on this study between August 1984 and July 1986. Three had favorable histology lymphoma on pathology review and were ineligible. Seven patients received only one course of treatment which was considered an inadequate trial. These patients are included in the analysis and assumed to have no response.

Patient characteristics and responses are presented in Table 1. Among thirty-two eligible patients, three achieved a complete remission (CR) and eight achieved a partial remission (PR), for an overall response rate of $34 \%$. The median overall survival from date of first treatment for all eligible patients was 6.4 months.

The characteristics of responding patients are presented in Table 2 . The median duration of complete responses was 4 months, and the median duration of partial responses was 7 months. Two of three complete responders had diffuse undifferentiated lymphoma, while 6 of 8 partial responders had diffuse poorly differentiated lymphocytic lymphoma.

Toxicity was severe. Fatal granulocytopenia oc- 
Table 2. Characteristics of responding patients

\begin{tabular}{|c|c|c|c|c|}
\hline & $\begin{array}{l}\text { Prior } \\
\text { therapy }\end{array}$ & $\begin{array}{l}\text { Risk } \\
\text { assessment }\end{array}$ & $\begin{array}{l}\text { Response } \\
\text { duration (mo) }\end{array}$ & Histology \\
\hline \multirow{3}{*}{$\begin{array}{l}\text { Complete } \\
\text { responders }\end{array}$} & $\mathrm{CHOP}$ & poor & 6 & DUL \\
\hline & $\mathrm{CHOP}$ & poor & 4 & DHL \\
\hline & m-BACOD & poor & 3 & DUL \\
\hline \multirow{8}{*}{$\begin{array}{l}\text { Partial } \\
\text { responders }\end{array}$} & CHOP-bleomycin & good & 12 & DML \\
\hline & CHOP & poor & 10 & DLPD \\
\hline & $\mathrm{CHOP}$ & poor & 9 & DLPD \\
\hline & CHOP & poor & 7 & DLPD \\
\hline & $\mathrm{CHOP}$ & poor & 7 & DLPD \\
\hline & COP-BLAM & good & 3 & DHL \\
\hline & m-BACOD & poor & 1 & DLPD \\
\hline & CHOP-araC & poor & 4 & DLPD \\
\hline
\end{tabular}

a CHOP = cyclophosphamide, doxorubicin, vincristine, prednisone; m-BACOD = methotrexate, bleomycin, cyclophosphamide, doxorubicin, vincristine, dexamethasone; COP-BLAM = cyclophosphamide, doxorubicin, vincristine, prednisone, bleomycin, procarbazine.

curred in one poor-risk patient, and 19 patients had life-threatening granulocytopenia $(63 \%)$. Moderate-to-severe toxicities included nausea/vomiting $(56 \%)$, thrombocytopenia $(31 \%)$, anemia $(25 \%)$, diarrhea $(6 \%)$, and mucositis $(9 \%)$. Renal toxicity was not seen.

\section{Discussion}

In this trial, combination chemotherapy with cisplatin, MGBG and mitoxantrone produced an overall response rate $(34 \%)$ comparable to that achieved by a variety of lymphoma salvage regimens, including others based on cisplatin and programs incorporating etoposide or cytosine arabinoside. The median duration of responses obtained (6.0 months) is likewise comparable to that seen in a recent report of a similar MGBG-based lymphoma salvage treatment [16]. It is interesting to note that $9 / 22$ patients receiving attenuated mitoxantrone doses because of anticipated poor marrow reserve responded to therapy, while only $2 / 10$ patients receiving full dose therapy responded. This difference is not statistically significant, but suggests that mitoxantrone contributed little to the antitumor activity of this regimen.

Responses were seen most frequently in the diffuse undifferentiated $(2 / 3)$ and diffuse poorly differentiated lymphocytic $(6 / 7)$ subtypes of unfavorable lymphomas in our study. In contrast, only $1 / 19$ patients with diffuse histiocytic and $1 / 3$ patients with diffuse mixed lymphoma responded.

Our results support further study of cisplatinum and MGBG combinations as salvage therapy for malignant lymphoma, particularly the diffuse poorly differentiated lymphocytic subtype.

\section{Acknowledgements}

This investigation was supported in part by the following PHS Cooperative Agreement grant numbers awarded by the National Cancer Institute, DHHS: CA-21116, CA-37429, CA-27057, CA13238, CA-35128, CA-35438, CA-35158, CA32102. The authors wish to thank Ms. Katie Hartley and Ms. Evonne Mize for careful data management and analysis.

\section{References}

1. Skarin AT, Canellos GP, Rosenthal DS, Case DC, Pinkus GS, Harrington DP: Moderate dose m-BACOD in advanced diffuse large cell lymphoma: An interim report. Adv Cancer Chemother, pp 23-30, 1986

2. Fisher RI, DeVita VT, Longo DL, Young RC: Treatment of 
diffuse aggressive lymphoma with PROMACE-based combination chemotherapy. Adv Cancer Chemother, pp 31-36, 1986

3. Connors JM, Klimo P: MACOP-B chemotherapy for the treatment of diffuse large cell lymphoma: 1985 update. Adv Cancer Chemother, pp 37-44, 1986

4. Schein PS, DeVita VT, Hubbard S, Chabner BA, Canellos GP, Berard C, Young RD: Bleomycin, Adriamycin, cyclophosphamide, vincristine, and Prednisone combination chemotherapy in the treatment of advanced diffuse histiocytic lymphoma. Ann Intern Med 95:417-422, 1976

5. Sweet DL, Golomb HM, Ultmann JE, Miller JB, Stein RS, Lester EP, Mintz U, Bitran JB, Stremli RA, Daly K, Roth NO: Cyclophosphamide, vincristine, methotrexate, with leucovorin rescue, and cytarabine combination sequential chemotherapy for advanced diffuse histiocytic lymphoma. Ann Intern Med 92:785-790, 1980

6. Kantarjian H, Barlogie B, Plunkett W, Valasquez W, McLaughlin P, Riggs S, Cabanillas F: High-dose cytosine arabinoside in non-Hodgkin's lymphoma. J Clin Onc 1:689-694, 1983

7. Cabanillas F, Hagemeister FB, Bodey GP, Freireich EJ: IMVP-16: An effective regimen for patients with lymphoma who have relapsed after initial combination chemotherapy. Blood 60:693-697, 1982

8. Ng RP, Todd D, Khoor KK: Salvage chemotherapy for nonHodgkin's lymphoma. Cancer Treat Rep 66:1977-1979, 1982

9. Warrell RP, Straus DJ, Young CW: Combination chemotherapy for patients with relapsed malignant lymphoma using methyl-GAG and Teniposide (VM-26). Cancer Treat Rep 66:1121-1125, 1981
10. Heinz R, Dittrich $\mathrm{CH}$, Ludwig $\mathbf{H}$, Kuhbock J, Wirth M, Baumgartner G, Waldner R, Schuller J: Results of a new combination chemotherapy (VIM-Bleo) in advanced nonHodgkin's lymphomas. (Abstr) Proc Am Soc Clin Oncol $6: 191,1987$

11. Dana BW, Jones SE, Coltman C, Stuckey WI: A phase II trial of m-AMSA, Cis-platinum, and MGBG in refractory lymphomas. Cancer Treat Rep 70:291-292, 1986

12. Van Echo DA, Whitacre MY, Aisner J, Wiernik PH: Phase I trial of dihydroxyanthracenedione. Cancer Treat Rep $65: 831-834,1981$

13. Coltman CA, McDaniel TM , Balcerzak SP, Morrison FS, VonHoff DD: Mitoxantrone hydrochloride in lymphoma. Invest New Drugs 1:65-70, 1983

14. Corbett TH, Robert BJ, Trader MW, Laster WR, Griswold DP, Schabel FM: Response of transplantable tumors of mice to anthracenedione derivatives alone and in combination with clinically useful agents. Cancer Treat Rep $66: 1187-1200,1982$

15. Miller AB, Hoogstratten B, Stagnet M, Winkler A: Reporting results of cancer treatment. Cancer 47:207-214, 1981

16. Warrell RP, Danieu L, Coonley CJ, Atkins C: Salvage chemotherapy of advanced lymphoma with investigational drugs: mitoguazone, gallium nitrate, and etoposide. Cancer Treat Rep 71:47-51, 1987

Address for offprints: Southwest Oncology Group (SWOG8369), Operations Office, 5430 Fredericksburg Road, Suite \#618, San Antonio, TX 78229, USA 